\title{
Effects of clay minerals on the formation of Mg-bearing calcium carbonate minerals
}

\author{
MR. ZSOMBOR MOLNÁR, PÉTER PEKKER, ISTVÁN \\ DÓDONY AND MIHÁLY PÓSFAI
}

University of Pannonia

Presenting Author: molnarzs1994@gmail.com

The highly charged surface and edge sites of swelling clay minerals (such as smectite) are able to bind ions or ion complexes, leading to the heterogeneous nucleation of carbonates from solution [1]. It is unclear, however, how environmental conditions (e.g. $\mathrm{pH}$ and solution composition) affect the carbonate nucleating potential of smectite, and whether the foreign surface plays any role in polymorph selection.

We performed titration experiments with an environmentally relevant experimental setup, in order to study the roles of swelling clay minerals in the formation of $\mathrm{Mg}$-bearing $\mathrm{CaCO}_{3}$ phases. We added both $\mathrm{Mg}$-free and $\mathrm{Mg}$-rich calcian solutions to carbonate buffer solutions both in the presence and absence of smectite, and monitored the evolution of the solutions with $\mathrm{pH}$ and $\mathrm{Ca}$ ion selective electrodes, in order to identify nucleation and phase transition events. After the titration experiments we aged the precipitated materials in their mother solutions for a few months. Both freshly formed and aged materials were studied using transmission electron microscopy (TEM).

Experiments with Mg-free solutions revealed that carbonate nucleation took place much earlier in the presence of smectite than in its absence, and the first crystalline phase was euhedral calcite. In contrast, from Mg-rich solutions aragonite precipitated both in the presence and absence of smectite. After aging the precipitated materials for months, Mg-bearing calcite-type phases appeared, but only in the presence of smectite. TEM tomographic analysis revealed that the Mg-bearing carbonates were included in composite particles of three different phases: (1) nanocrystalline platelets of 'protodolomite', assembled in fibrous structures, enveloping (2) a low-magnesian calcite core, with (3) nm-scale flakes of smectite included in both fibers and core. These observations suggest that if smectite is present in an environment where carbonates precipitate, the clay mineral has important and complex roles in the formation of $\mathrm{Mg}$-bearing calcium carbonate phases. In addition to enhancing the nucleation of the first carbonate solid, smectite also triggers the formation of calcite-type structures, both at nucleation and in dissolution/reprecipitation reactions during aging.

[1] Kralj D., Vdović N. (1999): The influence of some naturally occurring minerals on the precipitation of calcium carbonate polymorphs, Water Researches, 34(1), 179-184. 